\title{
Ethical dilemmas for general practitioners under the UK new contract
}

\author{
Lindsay F P Smith and J R Morrissy Graduate student and Associate Professor, University of Western Ontario, \\ Canada, respectively
}

\section{Authors' abstract}

Possible distributive justice frameworks for providing health care by general practitioners are discussed. The ethical considerations before and after the recent changes to the British National Health Service are contrasted, with particular emphasis on a possible ethical divide that has been produced between fund-holding and nonfund-holding general practitioners. It is argued that general practitioners in non-fund-holding practices can continue as ethical advocates for their patients and distribute health care within an egalitarian framework. However, those in fund-holding practices may now be seen as interest advocates and may have to practise utilitarian distributive justice. Patient groups may be needed to ensure that these general practitioners are seen to act justly in the distribution of the health care resources for which they are now responsible.

\section{Introduction}

British general practitioners provide comprehensive continuing primary medical care for their personal or group list of patients. They make many decisions each working day, ranging from how to care for people with common, self-limiting minor illnesses to major life-and-death decisions (1). When decisions are made about the medical care that a patient should receive, doctors have a duty to consider the various aspects of the decision: medical, legal, economic and ethical. Whether the recent 1991 National Health Service (NHS) changes have altered the ethical framework has received scant attention in the context of British general practice $(2,3,4,5,6)$. To debate this dimension we will first consider the ethical obligations that general practitioners have to their patients, and then consider whether the recent changes to the NHS have altered the ethical framework within which general practitioners decide how to care for their patients.

It has been stated that doctors have several obligations to their patients within the doctor-

\section{Key words}

Rationing; health care; general practitioners. patient relationship which are consequent to that relationship and in addition to the moral obligations that all human beings owe to one another (7). Doctors' moral obligations to their patients include respecting patient autonomy and avoiding harm (non-maleficence): both of these obligations are not consequent upon the presence of a doctor-patient relationship. Within the relationship, however, it is usual to consider non-maleficence together with the obligation to do good (beneficence) to one's patient because most medical treatment has potential for both good and harm. Doctors must weigh these two principles and judge what is the best course of action for that individual patient: that judgement can be made with the patient. Finally, doctors should be just in providing health care to patients, and such distributive justice should be reflected within the doctor-patient relationship.

There are various justice frameworks (8) within which general practitioners can discharge their obligation to be just in medical decision-making. Justice may be defined as 'giving to each his/her due'. 'Distributive justice' is a narrower concept and refers to the just distribution of some good in a cooperative society structured by various moral, legal and cultural rules and principles. This definition, however, begs the question, upon what basis should this just distribution be decided? There are various rival theories of justice which all share a minimal principle traditionally attributed to Aristotle: equals must be treated equally, and unequals must be treated unequally. In expanding Aristotle's principles of justice, Rawls (9) introduced the 'fair opportunity rule' with respect to the concept of fairness in distributing the benefits of society. Thus he argued that the basic benefits of a society should be available to the advantage of all members of that society, and should not be tied to office or position.

Beyond this minimal principle, the rival theories all differ in the principles which they use to decide how justly to distribute a good, ie, in how they decide relevant characteristics for equal treatment. Three of the most important theories of justice are egalitarian, utilitarian and libertarian theories. General practitioners adhering to egalitarian theories of justice would propose that persons should be 
given an equal distribution of health care: this means providing care to individuals which is commensurate with their needs and providing it equally to those with equal needs. Adherents of a utilitarian theory of justice would decide on the distribution of health care which produces greatest overall utility (results in the greatest benefit) to all, which may mean that an individual patient may receive less than optimal medical care in some circumstances. Finally, libertarian general practitioners would decide how justly to distribute health care based upon the unfettered free choice of individuals using freemarket principles. Thus, it can be seen that doctors adhering to these differing theories of justice will take into account different factors when deciding how justly to distribute health care.

One final ethical consideration is the nature of the doctor-patient relationship. When general practitioners interact with patients to provide them with medical care, the aim is to provide benefit to their health within the context of the doctor-patient relationship, ie, it is a fiduciary relationship. Doctors are behaving as ethical advocates in this relationship: ideally they are impartial in their decisions because their actions and decisions are made to benefit the patients and not to benefit themselves (10). Various models of the doctor-patient relationship exist, most notably the engineering, priestly, collegial and contractual/covenant models (11). However, all types are fiduciary in nature and simply vary in the relative importance that they place on the doctor's moral obligations of beneficence, non-maleficence, autonomy and justice. All four of these models include a moral obligation to be just to patients.

General practitioners need to acknowledge that medical resources are limited and thus they need to consider whether they must act as agents of distributive justice within society. It is this harsh economic reality which may also suggest that utilitarian principles might be relevant to the individual general practitioner caring for individual patients (12). This means that individual general practitioners might consider changing the weight attached to various ethical obligations when deciding the medical care that they provide to an individual patient. This may mean that for one patient, the utilitarian doctor does not provide all possible medical care (reduces individual beneficence and justice) so that scarce resources are available for a more needy patient (increases community beneficence). Such an approach would be contrary to the tradition in British general practice of simply considering each patient as an individual, not in relation to any other (13). How much this tradition was universally the case is debatable, in that to some extent it is likely that past general practitioners' decisions have been influenced by economic costbenefit analyses. However, in the past, general practitioners have not had a personal involvement in the cost-containment of the health care system.
Whether they should, in the future, have such a personal involvement, could be an increasingly important ethical consideration in the rationed NHS in which we practise (4).

\section{Rationing of health care}

If one is to consider what weighting to attach to differing ethical theories of distributive justice in the day-to-day decisions that general practitioners make in providing care (14), then it is important to consider the ways in which health care is at present rationed $(5,15)$, other ways of rationing $(16)$ and who decides on such resource allocation (17), bearing in mind that health care has always been rationed $(4,18,19,20,21)$.

Health care can be distributed in various ways: by criteria of age $(20,21)$, of wealth (as in the USA) (22), of time (as in UK NHS waiting lists), of historical precedent, of geography (regionalisation of certain services), or of government decree (for example, free Medicare for the elderly in the USA (23)). It can be allocated at different levels. At the macro-economic level the government can decide (a) how much of the country's gross national product (GNP) is spent on health care $(24,25)$, (b) how this is divided among the geographical areas the UK (to regional health authorities) (17) and (\& how much is to be spent on sub-divisions of health care, for example, on primary care, preventive care and tertiary care. Meso-allocation occurs within these sub-divisions: in the case of primary care, the regional and other health authorities will decide how primary-care spending is to be distributed between prescribing, referral costs, pathology investigation costs, staff costs, infrastructure, etc. Finally, the individual general practitioner will decide which patients are to be investigated, referred and/or treated: this is what we would term personal rationing (or micro-allocation). Historically, the British general practitioner has not been involved in impersonal rationing, (meso- and macro-allocation). This has been done by managers and politicians. However, there is some evidence that GPs have practised implicit personal rationing, at least in the $\frac{T}{O}$ area of referrals, for example, by referring fewer elderly, unemployed and single persons for $\stackrel{N}{\circ}$ expensive procedures such as renal transplants or coronary artery surgery $(18,19)$.

\section{Effects of NHS general practice changes}

Two areas of health care resource use in primary care are now considered as examples of how general practitioners' ethical considerations have been changed by the introduction of budget-holding in April 1991: prescribing and referral costs. The $\frac{\odot}{\mathbb{D}}$ effects that the NHS changes have had on fund- $\varnothing$ holding practice workload have been reported $(26,27,28,29)$, but their effects on the ethical 
framework within which general practitioners make decisions have received little attention.

Prior to the changes to the British NHS in April 1991, there was effectively no upper limit to the prescribing and investigation costs incurred by general practitioners when providing medical care to their patients. Referral outpatient appointments and subsequent non-emergency inpatient care were rationed by waiting lists, and some outpatient investigative procedures were also rationed by not permitting general practitioners free access to them: patients had to be referred through hospital specialists and thus time was again used to limit resources. In ethical terms there was no dilemma: usually general practitioners simply managed patients and made decisions to maximise the benefit to individual patients (they were acting justly within an egalitarian framework). However, even before the changes, there is some evidence that general practitioners were nevertheless acting along utilitarian lines by not referring certain types of patient when there was less expectation that they could obtain benefit from a referral, for example, not referring elderly patients for renal dialysis (19).

To summarise the discussion to this point, prior to 1991 general practitioners usually decided how to distribute health care to their patients within an egalitarian theory of justice; the essential nature of the doctor-patient relationship was fiduciary and individual general practitioners did not decide how to allocate health care at the meso- and macroeconomic levels.

Since April 1991, practices of sufficient size have been able to choose to run as either fund-holding practices (FHPs) or as non-fund-holding practices (non-FHPs). Whichever they have chosen they have been limited in terms of the budget of NHS resources that they can consume each year in order to provide care for their patients. The general practitioners in FHPs have been given management control of certain parts of the total NHS resources which they will use to provide patient care. They have been given overall budgets for their prescribing costs, outpatient referrals (specialists, para-medical care, for example, physiotherapy, pathology and radiology investigations), some inpatient procedures, for example, routine orthopaedic surgery, and practice staff costs (26). This means that they decide how to allocate resources within these budget heads at a mesoeconomic level, which is an innovation.

In contrast, the general practitioners in non-FHPs do not have this management control: the management decisions about expenditure under these budget heads are made by either the District Health Authority (DHA) or the Family Health Service Authority (FHSA) or by new combined purchasing or 'commissioning' authorities, on behalf of the general practitioners (for both large nonFHPs and all other practices who are too small to be eligible to elect to be FHPs).
It must be considered how these devolutionary changes in the control of budgets have affected the ethical framework within which general practitioners make decisions about patient care.

First, all general practitioners are now ethically obliged to consider if they are acting with beneficence. Second, they may need to consider acting in a more utilitarian way when deciding on the management (19) (decisions about referral, investigation and treatment) of individual patients. Such action is only justified if reducing costs incurred in caring for one patient by providing less than the maximum possible care, ie, acting with less distributive egalitarian justice, will provide otherwise unavailable resources for other patients within their practice, or for the same patient at a different time, thus increasing utilitarian beneficence. When considering this ethical dilemma, general practitioners need to be careful about the justice framework within which they are attempting to maximise benefit to most individuals. Is the general practitioner considering simply potential utilitarian benefit only to his/her practice's patients or to all patients within the locality (for example, within the DHA or FHSA boundary) or to all NHS patients or is s/he restricting benefit only to NHS patients? One can argue that the general practitioner should consider potential utilitarian benefit limited to either his/her own patients or to patients in the locality.

\section{DRUG COSTS}

Prior to the changes in the NHS, every general practitioner could prescribe unlimited amounts of drugs from the limited drug list which the government had unilaterally introduced some years before in a previous attempt to limit government drug costs. The Department of Health bore all prescription costs except for a small fixed prescription charge, which a minority of patients paid towards the cost of the drug, which was independent of the cost of the drug. At this time there was little reason for a general practitioner to limit his/her prescribing in either total number of prescriptions or in cost of individual prescriptions. Indeed both beneficence and egalitarian justice would compel general practitioners to prescribe to maximal effect for each of their individual patients. It must be noted, however, that such freedom from other considerations may have led to inappropriate prescribing. But this possibility does not detract from the fact that in reality there was no cash limit on primary care prescribing costs.

Following the 1991 changes all general practitioners have individual indicative drug budgets within which they are expected to keep for the year. These are based upon the previous year's budget but may be altered by the FHSA's medical adviser to take into account peculiarities of the individual general practitioner's practice population: these alterations are based on norms and as such have little 
scientific basis, much like the indicative budget itself. What would happen if the general practitioner did indeed 'save' money by spending less on prescribing than expected (by limiting egalitarian justice but in the hope of maximising utilitarian justice)? Who would decide for what purpose the money saved should be used? The answer is different for FHPs and non-FHPs and this means that the ethical considerations facing GPs, about whether to limit their prescribing of efficacious treatments in clinical situations are different.

First, consider non-FHPs. By following utilitarian principles, if resources are saved by not providing maximum beneficial care for some patients, this 'saving' may be used to provide more care for other patients. If at the end of the year the overall drug budget is underspent then such a practice has no control over the use of these savings. The FHSA, who originally set the indicative drug budget, have control. Such savings might be used for many purposes. For example, the savings might be used to pay for drug treatment for another patient in another practice, or they might be used to fund other parts of primary care, for example, extra practice staff, or they might even be used to assist the FHSA to fund its own administration costs. If a non-FHP general practitioner overspends the budget then this is covered by the regional health authority providing extra funds and the chief officers of the FHSA do not get their performance-related pay bonus. There is therefore only a weak positive utilitarian argument (16) in favour of the non-FHP general practitioner changing (= restricting) his/her prescribing habits in order to save money. If an overall saving is achieved by a practice, it is unlikely that patients of that practice will benefit and indeed no patient may benefit if the saving is used for health authority costs.

General practitioners in FHPs are in a different situation. If money is saved overall on the indicative drug budget then the surplus is controlled by the practice and can be spent on any practice-related use, for example, extra referrals or approved changes to their premises. It is much clearer here that these general practitioners have a stronger utilitarian duty to try and save money on their prescribing budget because their own patients will benefit from such savings, for example, the money could be used to fund a practice physiotherapist. But the general practitioners themselves might also benefit and this potential benefit pushes the ethical nature of individual doctor-patient relationships away from a fiduciary one. How might doctors stand to benefit? Consider the case where general practitioners wish to fund improvements to their premises. FHP general practitioners could subsidise the costs of such improvements using funds saved on prescribing, whereas non-FHP general practitioners could not do this. That is not to say that the FHP doctor would act in this way but it is a possibility. This possibility of virement within the overall budget, changes the doctor's relationship to the patient from that of ethical advocate to one of interest advocate: from a doctor who cannot benefit personally from the decision of how to care for the patient to a doctor who might benefit $(6,11)$.

\section{REFERRALS}

Prior to the changes in the NHS, any general practitioner could refer any patient to any NHS hospital in the United Kingdom. For nonemergency care, this meant that provided a patient was prepared to travel there was relatively little geographical rationing of care although it was limited by time and by the use of waiting lists both for outpatient appointments and routine surgery. However, most referrals were made to a hospital near the patient's home, often the closest. The patient's choice (autonomy) and distributive justice were thus minimally limited.

After the 1991 changes, the clinical freedom of $\vec{c}$ the general practitioner to refer to any hospital was severely curtailed for non-FHPs but not for FHPs: distributive justice was thus impaired and patient autonomy limited for the patients of non-FHPs. The changes were made by politicians, based on the $\overrightarrow{0}$ theory that they would lead to greater efficiency the NHS through competition, thus enabling more patients to be treated at the same cost. In othes words, the politicians were trading reduced patient choice and justice for a theoretical gain in beneficence for all patients.

Contracts now have to be negotiated with any hospital prior to referral of patients for a wide range of outpatient and non-emergency inpatient care. In the case of non-FHPs, the DHA does the negotiation on behalf of the general practitioners; for FHPs the general practitioners do the negotiation themselves.

If non-FHPs as a whole refer fewer patients than expected then the DHA saves money which it can then spend on other aspects of health care: as with drug-prescribing savings made by non-FHP general 0 practitioners it can be argued that their need to $>$ consider utilitarian ethical principles is not strong. If the general practitioners of an FHP save money on referrals then they can use the money for other o purposes within the practice. As with prescribing $N$ there is a strong case for them to consider utilitarian $N$ principles in individual consultations by considering 0 that the greatest good may mean not referring $a_{0}$ particular patient. Moreover, FHP general prac- $\frac{\bar{\Phi}}{\Phi}$ titioners are again acting as interest rather than $\stackrel{\oplus}{?}$ ethical advocates in terms of referral decisions (30). 7

\section{Ethical implications of the changes}

The ethical decisions that general practitioners are $\frac{0}{\sigma}$ increasingly having to make, particularly in terms of distributive justice, underline the need for adequate 
education both at undergraduate and postgraduate levels for those who are to become general practitioners. Indeed, it can be argued that all doctors would benefit from an increased awareness of the various ethical and economic theories and potential conflicts that they will meet in their practice.

There is a need for ethical safeguards beyond those provided by an adequate grounding of general practitioners in ethics, for those who practise in fund-holding practices. There is the possibility of unethical use of health care resources in these practices where the general practitioners have such control of health resources for their practice population. Not only must distributive justice (and beneficence) be practised but it must also be seen to be practised. One way to ensure that resources are used ethically would be to involve patient participation groups, working as mini-community health councils, in a practice's decisions on how to use any savings on individual budgets. In addition, if budgets are overspent, such groups could also have input into which services should be further rationed by the practice. There is an existing model for such an approach in Quebec, Canada. In that province there exist community health centres which have a lay board of directors which decides, together with salaried doctors, on priorities for patient care and service development.

\section{Summary}

British general practitioners have historically acted as ethical advocates for their patients and have not usually considered utilitarian ethical principles when making decisions about the care of individual patients. Implicitly, they have made management decisions based on the moral obligations of egalitarian distributive justice and assumed beneficence and non-maleficence; patient autonomy has often been a minor consideration. The changes to the NHS introduced unilaterally by the government has changed the ethical framework within which general practitioners now make decisions about prescribing, patient referral and investigation. There is now an obligation upon general practitioners in FHPs to consider utilitarian principles when deciding about how justly to distribute health care (within the doctor-patient relationship). Also because they may benefit personally from their decisions they are now interest and not ethical advocates and the essential nature of the relationship may no longer be fiduciary: these two changes may alter the perception that their patients hold of them, and consequently affect the doctor-patient relationship from the patient's side as well. General practitioners in non-FHPs can continue to practise within the same justice framework as before the changes, although it could be argued that even they need to consider utilitarian principles in their decision-making, though the case is weaker than for FHP general practitioners.

Both groups of general practitioners now have a more important ethical duty to consider the consequences of their clinical decisions to ensure that they are truly acting with beneficence, nonmaleficence, and with distributive justice, because of the overall rationing of primary-health-care resources since the changes to the NHS.

The participation of patient groups, perhaps as mini-community health councils, in the just distribution by the practice of any savings and in the just rationing in case of overspends to the total practice patient population, might increase the possibility that justice is seen to be done, as well as being done.

\section{Acknowledgements}

We would like to thank Dr Brian Hennen and Dr Michael Whitfield for their helpful criticism of the manuscript, and Ms Lynn Dunikowski and her staff at the Canadian Library of Family Medicine for their help with this study.

Lindsay F P Smith, BSc, MClinSci, MRCGP (UK), is a Research Fellow in the General Practice Unit of the University of Bristol. $\mathcal{F} R$ Morrissy, FCFP, is Professor of the Department of Family Medicine at the University of Western Ontario, London, Ontario, Canada.

Address for correspondence: $D r$ Lindsay F P Smith, 17 Church Street, Ilchester, Somerset, BA22 8LN.

\section{References}

(1) McWhinney I. A textbook of family medicine. Oxford: OUP, 1989.

(2) Rabkin M T. Cost containment - ethical implications. Fournal of the American Geriatric Society 1992; 40: 413-416.

(3) Robillard H M, High D M, Sebastian J G, Pisaneschi J I, Perritt L J, Mahler D M. Ethical issues in primary care: a survey of practitioners' perceptions. fournal of community health 1989; 14: 9-17.

(4) Toon P. Rationing resources in the new NHS. Practitioner 1991; 235: 488-490.

(5) Jecker N S, Berg A O. Allocating medical resources in rural America: alternative perceptions of justice. Social science and medicine 1992; 34: 467-474.

(6) Smith H L. Medical ethics in the primary care setting. Social science and medicine 1987; 25: 705-709.

(7) Gillon R. Doctors and patients. British medical journal 1986; 292: 466-469.

(8) Beauchamp T L, Childress T F, eds. Principles of biomedical ethics. Oxford: Oxford University Press, 1989.

(9) Rawls J. A theory of justice. Cambridge, Massachusetts: Harvard University Press, 1971.

(10) Christie R J, Hoffmaster C B. Ethical issues in family medicine. Oxford: OUP, 1986.

(11) Arras J, Rhoden N. Ethical issues in modern medicine. Mountain View, California: Mayfield Publishing Company, 1989. 
(12) Williams A. Cost-effectiveness analysis: is it ethical? Fournal of medical ethics 1992; 18: 7-11.

(13) McKinstry B. Paternalism and the doctor-patient relationship in general practice. British journal of general practice $1992 ; 42$ : 340-342.

(14) Menzel P T. Some ethical costs of rationing. Law, medicine and health care 1992; 20: 57-66.

(15) Delamothe T. Getting rational over rationing. British medical journal 1992; 305: 1240-1241.

(16) Wilker D. Ethics and rationing: 'whether', 'how', or 'how much'. Fournal of the American Geriatric Society 1992; 40: 398-403.

(17) Reagan M. Health care rationing: a problem in ethics and policy. Fournal of health politics, policy and law 1989; 14: 627-633.

(18) Horvath D G. The ethics of resource allocation. Medical journal of Australia 1990; 153: 437-438.

(19) Smith R. Rationing: the search for sunlight. British medical journal 1991; 303: 1561-1562.

(20) Engelhardt H T. Medical ethics for the 21 st century. Fournal of the American College of Cardiology 1991; 18: 303-307.

(21) Kilner J F. Age as a basis for allocating lifesaving medical resources: an ethical analysis. Fournal of health politics, policy and law 1988; 13: 405-423.
(22) Higgins W. Rationing medical care. Family medicine 1991; 23: 292-295.

(23) Dixon J. US health care I: the access problem. British medical journal 1992; 305: 817-819.

(24) Jeckner N S, Pearlman R A. An ethical framework for rationing health care. fournal of medicine and philosophy 1992; 17: 79-96.

(25) The ethics of resource allocation. Fournal of $\overline{\bar{C}}$ epidemiology and community health 1990; 44: 187190.

(26) Bain J. The new NHS. Budget holding: a step into ڤึ the unknown. British medical journal 1991; 302: 771-773.

(27) Bain J. Budget holding: the first 150 days in Calverton. British medical journal 1991; 303: 907-908.

(28) Bain J. Budget holding in Calverton: one year on. British medical journal 1992; 304: 971-973.

(29) Hannay D R, Usherwood T P, Platts M. Practice $\omega$ organisation before and after the new contract: $a \vec{V}$ survey of general practices in Sheffield. British journal $\mathrm{G}$ of general practice 1992; 42: 517-520.

(30) Marinker M, Wilkin D, Metcalfe D H. Referral to $\rightarrow$ hospital: can we do better? British medical journal $\odot$ 1988; 297: 461-464.

\section{News and notes}

\section{Randomised controlled trials: ethical and legal issues}

A two-day course for doctors, nurses and members of research ethics committees to consider the ethical and legal implications of undertaking randomised controlled trials will be held at the British Postgraduate Medical Federation (BPMF) Central Office, 33 Millman Street, London WC1N 3EJ, on the 22nd and 23rd of November 1994.

Sessions covering the rationale and need for controlled trials, how they impinge on the doctor/patient relationship, and the ethical and legal considerations which result will be taken by Professor Michael Baum, Mrs Joan Houghton, Dr Lesley Fallowfield, Mrs Angela Hall, Dr Raanan Gillon, Mrs Claire Gilbert Foster and Mrs Diana Brahams. Each session will include a lecture and workshop or discussion time. Participants will be invited to present cases of particular interest for discussion.

The course is non-residential but information on accommodation can be provided.

In order to achieve an informal approach numbers will be limited, so early application is advisable.

The course fee is $£ 198$ and includes meals and refreshments. (PGEA approved: 12hrs Service Management.)

Further details and application forms are available from: Education Department, BPMF, 33 Millman Street, London WC1N 3EJ. Tel: 071-831 6222 ext 155 or 071-405 5660 (24hr answerphone). Fax: 071-831 1387. 